\title{
Análise do discurso amoroso em contos ilustrados: uma contribuição para a sociologia das emergências
}

Beatriz dos Santos Feres ${ }^{\mathrm{a}}$ (D)

\section{RESUMO}

Segundo Boaventura de Sousa Santos (2020), as sociologias das ausências e das emergências situam-se no cerne da resistência contra o pensamento hegemônico ocidentalocêntrico a fim de não só identificar as formas por meio das quais são produzidas a não existência, a invisibilidade radical e a irrelevância de grupos sociais oprimidos, mas também de valorizar simbólica e politicamente os saberes das minorias advindos da luta, da experiência, do sofrimento injusto, da corporalidade e do "corazonar", isto é, da racionalização "quente", afetiva. Este artigo está direcionado, em particular, para as sociologias das emergências, com a pretensão de contribuir para a instrumentalização de mediadores críticos de leitura, preocupados com a resistência a um imaginário coletivo preconceituoso em relação às minorias sociais. Assim, o objetivo desta reflexão é problematizar o conto ilustrado - bem cultural destinado preferencialmente às crianças em estágio inicial de socialização e, portanto, mais susceptíveis à inculcação de valores -, analisando sua constituição verbo-visual singular em relação

\section{Como citar:}

FERES, B.S. Análise do discurso amoroso em contos ilustrados: uma contribuição para a sociologia das emergências. Gragoatá, Niterói, v.26, n.56, p. 985-1017, 2021.<https://doi.org/10.22409/ 
ao contrato de comunicação a que se vincula, a fim de avaliar sua potencialidade como recurso para uma pedagogia libertadora. Parte-se do pressuposto de que a configuração híbrida do conto ilustrado permite uma complexa implicitação de sentidos e sentimentos bastante propícia para o tratamento estético de temas relacionados às sociabilidades, sem que se perca a poeticidade, em um movimento aparentemente afinado ao "corazonar" defendido pelas epistemologias do Sul. Para isso, a análise dos contos ilustrados selecionados estará sustentada, prioritariamente, pela Teoria Semiolinguística de Análise do Discurso, sobretudo naquilo que tange à construção dos imaginários sociodiscursivos.

PALAVRAS-CHAVE: Sociologia das emergências. Corazonar. Semiolinguística. Discurso amoroso. Contos ilustrados.

\section{Do "corazonar" ao discurso amoroso}

[...] a sociologia das emergências tem de ser transescalar para poder desempenhar o seu papel pedagógico e mobilizador da vontade inconformista. (SANTOS, 2020, p. 353)

Boaventura de Sousa Santos (2020), engajado na disseminação das epistemologias do Sul - isto é, no esforço para reformular o pensamento, migrando da hegemonia ocidentalocêntrica para um pluriverso menos desigual e opressor - defende que, para além de identificar os meios e as formas de colonizar grupos sociais e suas culturas que realizam um epistemicídio a favor da não existência, da invisibilidade radical e da irrelevância dos grupos oprimidos, é urgente promover ações para afirmar os saberes das minorias, nascidos de sua luta por visibilidade, por voz e por vez, por seu direito de ser "completamente humano".

Entre as várias ações possíveis, Boaventura defende a necessidade de tornar fecunda a "sociologia das emergências", isto é, aquela que, complementando e ultrapassando a denúncia promovida pelas "sociologias das ausências", tem o objetivo precípuo de mobilizar a "vontade inconformista" daqueles que tomam consciência de seus direitos. Com esse intuito, 
a "sociologia das emergências", segundo ele, é (ou deve ser) transescalar. Assim, ela consegue articular "as potencialidades, latências, possibilidades aceitáveis de resistência eficaz contra a dominação", "detectáveis no terreno concreto em que vivem os grupos sociais oprimidos, ou seja, no nível da microescala", à macroescala com que trabalham as "sociologias das ausências" (SANTOS, 2020, p. 353), cujas investigações incidem sobre períodos históricos longos e vastos campos sociais, com o intuito de identificar as sociabilidades metropolitana e colonial (para além do colonialismo histórico) nas quais ainda se baseia, na atualidade, o pensamento hegemônico europeu.

Em outras palavras, dialogando com a Pedagogia do oprimido de Freire (2018), o que propõe Santos (2020) é partir da concretude das lutas do dia a dia, por pontuais que possam ser, transformando-as em exemplos de alternativas "que, sendo possíveis num tempo e num lugar, podem ser igualmente possíveis noutro tempo e noutro lugar" (2020, p. 353), com a finalidade de alcançar a "descolonização" do pensamento ocidentalocêntrico, das relações sociais e culturais opressivas, e promover novas aprendizagens fundamentadas em muita escuta e troca, que deem lugar aos grupos oprimidos e historicamente silenciados e invisibilizados.

Trata-se de um empreendimento que, nascido nas lutas contra o colonialismo histórico da segunda metade do século passado, espraia-se para a resistência à colonialidade do pensamento em geral, herdada por uma lógica social e cultural caracterizada pela relação entre dominadores e dominados, humanos e sub-humanos (estes desumanizados pelo pensamento colonial, hierarquizados subalternamente como aqueles que não têm direitos, nem precisam ser dignos de respeito). Na América Latina, cresce o movimento na direção de um pensamento decolonial com cores próprias, centrado em histórias de sociabilidades marcadas pelo epistemicídio e pelo genocídio de povos indígenas e de escravizados, que reverberam nas relações sociais ainda fortemente constituídas pelo colonialismo, pelo capitalismo e pelo patriarcado.

Soma-se a essa proposta a "ecologia dos saberes", que, de acordo com Boaventura, inclui saberes "artesanais" e novos repertórios (muitas vezes nascidos na ancestralidade dos povos) que começam a ultrapassar o espaço dos grupos sociais de origem para diversificar narrativas e contribuir na concepção de 
um mundo mais justo, a partir de uma polifonia efetivamente "pluriversal" do pensamento. Ao lado de conceitos como o sulafricano ubuntu, "ser-com" e "estar-com" ("Eu sou porque és"), ou do conceito-chave quéchua de chachawarmi, que "designa uma noção igualitária e complementária de relações entre os sexos, dispensando os padrões e as linguagens subjacentes ao feminismo eurocêntrico" (2020, p. 30), Boaventura investe na ideia de "corazonar", do "aquecimento da razão", isto é, da "razão que vive bem com emoções, afetos e sentimentos sem perder a razoabilidade" (2020, p. 35). É com interesse nesses pontos, nas sociologias das emergências, na ecologia dos saberes que inclui a opção por uma razão com afeto, na necessidade de descolonizar o pensamento e promover epistemologias "pluriversais", que nasce a reflexão proposta neste artigo.

Nosso objetivo aqui, vinculado ao processo de mediação leitora escolarizada (sobretudo), é problematizar o conto ilustrado como bem cultural de destinação preferencial à infância, especialmente aquele que veicula um discurso amoroso. Pretende-se avaliar sua potencialidade como recurso para uma pedagogia libertadora, que, segundo Freire (2018, p. 43), faz “da opressão e de suas causas objeto da reflexão dos oprimidos, de que resultará o seu engajamento necessário na luta por sua libertação", ou, em outras palavras, uma pedagogia preocupada com a resistência a um imaginário coletivo preconceituoso e opressor em relação às minorias sociais, afinada com "o fim do império cognitivo" defendido por Santos (2020).

Esse bem cultural - o conto ilustrado - ainda que esteja vinculado a espaços variados de troca pedagógica como o doméstico, ou o das salas e rodas de leitura, é na escola como instituição, constituída de elementos ideológicos, econômicos e políticos, isto é, como instância instituinte, capaz de influenciar a realidade social (NADAL, 2011), que encontra seu espaço de circulação mais relevante. Apesar de muitas vezes ingenuamente relacionado a um universo de mero entretenimento, o conto ilustrado pode ser, por um lado, um instrumento de perpetuação de valores muitas vezes opressores, mas, por outro, um recurso para a reconfiguração dos imaginários sociodiscursivos, ou ainda para a proposta de novos modos de ver, por meio de uma prática dialógica e reflexiva, voltada para a autonomia do pensamento. 
Vale salientar que, embora, nesta reflexão, o discurso amoroso não se refira a um "discurso de enamorados", como em Barthes, herda-se, de seu Fragmentos de um discurso amoroso, a necessidade de sustentar um discurso "abandonado pelas linguagens circunvizinhas [...], excluído não somente do poder, mas também de seus mecanismos (ciências, conhecimentos, artes)", restando-lhe somente o exíguo lugar de uma afirmação (BARTHES, 1988, prefácio). Trata-se, aqui, do discurso amoroso direcionado para a conscientização e para a valorização das minorias sociais.

Com esse ponto de vista, acredita-se ser possível direcionar a Análise do Discurso, quase sempre voltada para as "sociologias das ausências", desvelando imaginários carregados de preconceito e de hierarquias sociais bem marcadas, para um trabalho relacionado às "sociologias das emergências", analisando estratégias de implicitação de sentidos e de afetos "afirmativos" em contos ilustrados como parte da instrumentalização da mediação em leitura - trabalho realizado na microescala de que fala Boaventura; no chão da escola, preferencialmente. Acredita-se que, com isso, a pesquisa acadêmica possa contribuir, ainda que indiretamente, para a validação de saberes e de lutas relacionados à resistência social.

A opção por um corpus formado por contos ilustrados se justifica de duas maneiras: primeiro, por circularem em espaços sociais próprios da fase inicial de socialização na infância (especialmente, na escola), no momento de inculcação de ideias e valores sem o filtro da criticidade e, portanto, de fácil adesão inconsciente; segundo, por serem constituídos por uma semiose verbo-visual complexa, que expressa, mais mostrando do que dizendo, ideias e sentimentos indissociáveis e, por isso, comunicam afetivamente visões de mundo.

Para esta reflexão, especificamente, interessa-nos analisar os mecanismos semiodiscursivos que, em geral, constituem o gênero conto ilustrado com o objetivo de salientar sua potencialidade para fazer saber, fazer sentir e fazer crer, aparentemente tão propícia para o "corazonar", ou para a percepção de sentidos e de sentimentos em prol de uma reformulação do pensamento.

O corpus para análise é composto por dois contos, selecionados em função de um eixo temático: a identidade da menina/mulher negra. São eles: Uma princesa nada boba, de Luiz 
Antonio, com ilustrações de Biel Carpenter (2011) e Amoras, escrito pelo rapper Emicida e ilustrado por Aldo Fabrini (2018). Outros contos - Flicts, de Ziraldo (1999) e Super, de Jean-Claude Alphen (2017) - serão mencionados em função de um ou outro aspecto relativo à implicitação de sentidos, mas não serão alvo de análise propriamente dita.

A investigação estará orientada prioritariamente por conceitos postulados pela Teoria Semiolinguística de Análise do Discurso; mais especificamente, pela noção de imaginário sociodiscursivo (CHARAUDEAU, 2006), com a qual será possível verificar, nos textos selecionados, mecanismos de implicitação de um pensamento decolonial, a favor da afirmação de ideias e valores oriundos das lutas de minorias, quase sempre observáveis no modo descritivo de organização do discurso (CHARAUDEAU, 2008) e nas visadas discursivas para fazer saber, fazer sentir e fazer crer. Com o foco na relação entre forma e conteúdo mergulhada em uma situação de comunicação específica, a Semiolinguística oferece recursos para a identificação de estratégias leitoras favoráveis à reflexão e à crítica de grande valor para a mediação leitora.

\section{Para descolonizar o pensamento}

Qualquer um que se interesse em como as ideias - politicas no sentido mais amplo e importante - são nutridas em uma sociedade não pode se dar ao luxo de negligenciar o que as crianças leem. (DIXON, 1977, apud HUNT, 2010, p. 207)

Em 1969, Ziraldo publica Flicts, considerado um marco na Literatura brasileira destinada às crianças e um modelo de livro ilustrado. Em geral, é essa a designação dada às obras, em geral destinadas às crianças, constituídas por uma relação quase sempre complementar entre palavra e imagem, isto é, nas quais a comunicação se realiza por meio de uma semiose dupla, verbo-visual. $\mathrm{O}$ texto, portanto, é constituído por uma parcela verbal e outra, imagética; a omissão de uma das parcelas pode ferir o sentido global do texto.

Ainda que essa definição não seja totalmente consensual, é ela que prevalece nos estudos críticos relacionados a esse gênero discursivo. Prefere-se, neste trabalho, a denominação conto ilustrado, por parecer se referir de modo mais ajustado a um gênero discursivo específico, constituído por narrativa verbal e 
imagética, de caráter literário, cujas linguagens convergem mais ou menos complementarmente para a construção do sentido global. Dessa maneira, evita-se a mistura de suporte - livro com gênero, "modelo" abstrato ao qual um texto pode aderir de acordo com sua forma, seu estilo e com a intencionalidade que o constitui.

Flicts, então, é considerado um exemplo prototípico de conto ilustrado. Nele, a história da "cor muito rara e muito triste que se chamava Flicts", o "frágil e feio e aflito Flicts" (ZIRALDO, 1999, p. 5 e p. 11), é contada por meio de palavras e de imagens, tomando por protagonista uma cor, "sem lugar no mundo", que decide sumir por causa da rejeição social em relação à sua diferença, e acaba se realizando na Lua, cuja cor é efetivamente flicts, segundo depoimento do astronauta Neil Armstrong (que finaliza o livro). É uma narrativa que alcança (também) o interesse de crianças pequenas, tanto pela personagem, quanto pelo tema relacionado à socialização.

A adesão à proposta dessa narrativa, por parte do leitor, mostra-se, em geral, bastante positiva. Os recursos visuais, como a intensidade das cores, a proporção que ocupam nas páginas (Flicts sempre espremido no canto), as figuras simbólicas em que as cores se materializam (o arco-íris, as bandeiras nacionais, o semáforo), o ritmo da narrativa, a parcela verbal concisa e de fácil referência ao mundo, tudo isso colabora para mostrar a discriminação sofrida por Flicts e para captar o leitor por meio de inferências intelectivas e afetivas relacionadas à rejeição: o conto mais mostra do que diz.

A qualidade da obra justifica seu sucesso ao longo de tantos anos, de tantas adaptações para o teatro, de tantas novas edições em diversas línguas. No entanto, a não reatividade do protagonista Flicts diante da discriminação que sofre - embora a narrativa deixe evidente o sofrimento do segregado e possa criar empatia no leitor - também escancara a imobilidade que, em geral, toma conta do indivíduo ao ser rejeitado socialmente - e que é combatida pelo pensamento decolonial. A opressão social anula o oprimido; silencia-o; invisibiliza-o, até que ele acredite em sua incapacidade de pertencer ao grupo.

Segundo Esteves (2016), especialista em Sociologia da Comunicação, na primeira fase de socialização da criança, ao mesmo tempo em que aprende a utilizar a linguagem (e, em parte, por causa dela), são fixados esquemas interpretativos e 
emocionais com valor institucional, que funcionam como "guias práticos para orientação prospectiva". A realidade interiorizada nesse primeiro acesso à realidade torna-se um estatuto obrigatório e se confunde com seu mundo. Não desenvolvendo, mais tarde, a criticidade necessária para o questionamento dessas "verdades" iniciais, muito do que o indivíduo absorve nessa fase da vida pode vir a se cristalizar como pensamento único, imutável. Na leitura de Flicts, a adesão ao sofrimento do discriminado pode, por um lado, provocar uma reação positiva (esperada, claro), com a necessária reação para incluir o indivíduo diferente, mas, por outro, ao mostrar um mundo tão cruel, que exige uma homogeneidade inalcançável para muitos, pode transformar a diferença em um veredicto quase fatal.

Dialogando com a tese sustentada por Esteves (2016), Colomer (2017), especialista em Literatura Infantil e Juvenil, defende que a literatura voltada para crianças e jovens (antes de tudo, Literatura), além de desenvolver a linguagem por meio de formas narrativas, poéticas e dramáticas do discurso literário, apresenta as funções de iniciar o acesso ao imaginário compartilhado de um grupo social e de oferecer uma representação articulada da realidade que serve de instrumento de socialização.

Destaca-se, aqui, que, para a estudiosa, adotando a perspectiva da Psicologia, o imaginário é definido como o "imenso repertório de imagens, símbolos e mitos que nós humanos utilizamos como formas típicas de entender o mundo e as relações com as demais pessoas" (COLOMER, 2017, p. 20). De acordo com essa perspectiva, os arquétipos, comuns a toda a humanidade, seriam formados a partir dessas imagens. O trabalho com contos de fadas, por exemplo, comprova a importância desse aspecto.

Entretanto, há uma perspectiva diferente, preferida, sobretudo, pelas teorias sociais, que vincula o imaginário a uma historicidade, a um tempo e a um lugar, entendendo-o como um repertório de imagens, ideias, comportamentos que dá identidade a cada grupo de indivíduos e cria um sentimento de pertença. Por isso, Colomer também pode afirmar que "não há melhor documento que a literatura infantil para saber a forma como a sociedade deseja ver-se a si mesma" (COLOMER, 2017, p. 62). Nos bens culturais oferecidos às crianças, como os contos ilustrados, tomados por objeto de análise, espelham-se 
crenças, valores, rotinas, comportamentos que vão identificar aqueles que pertencem a um determinado grupo.

A Semiolinguística, situada como uma Análise do Discurso, enfatiza o caráter socializador dos imaginários que, nessa teoria, são definidos como "sociodiscursivos".

Por mais que se fale (ou escreva) com a finalidade essencial de estabelecer uma relação entre si e o outro e de influenciá-lo, tentando persuadi-lo ou seduzi-lo, essa relação seria vazia de sentido se não tivesse por objeto certa visão que trazemos do mundo, isto é, o conhecimento que se tem da realidade e os julgamentos que dela se fazem. O homem é tomado tanto por um desejo de inteligibilidade do mundo quanto de troca com o outro. (CHARAUDEAU, 2006, p. 187).

Na linguagem, os imaginários, constituídos por saberes de conhecimento e de crença organizados em sistemas de pensamento, dispõem as representações de acordo com o modo de ver de uma coletividade. Em cada ato de linguagem, a "visão que trazemos do mundo" não só regula as maneiras de dizer, mas também estabelece um vínculo interacional favorável à troca comunicativa. Os interagentes precisam reconhecer as referências feitas à realidade, assim como perceber as avaliações a respeito dela. De acordo com Charaudeau (2006), o imaginário sociodiscursivo, no quadro da Análise do Discurso, assume o papel de espelho identitário e, para isso, materializa-se em comportamentos, atividades coletivas, objetos manufaturados, símbolos "emblemáticos", provérbios etc.

[...] é pelo olhar dos outros que somos marcados, etiquetados, categorizados: nossas vestimentas, nossa maquiagem, nosso peteado, nossa linguagem, nosso andar, e o que o nos é mais inerente, como o sexo e a idade, tudo isso atesta nosso pertencimento a uma categoria de indivíduos, o que permite aos outros classificar-nos neste ou naquela categoria. (CHARAUDEAU, 2015, p. 15)

É também o imaginário sociodiscursivo que permite a identificação, nos textos que circulam na sociedade - também nos contos ilustrados, portanto -, das orientações ideológicas mais conservadoras, ou mais progressistas, entre outras. Por exemplo, em Super, de Jean-Claude Alphen (2017), o ponto de vista do menino-narrador mostra um pai super-herói, vestido de capa, que sai voando todos os dias para trabalhar. A mãe, 
"nada heroína", leva o menino para a escola, vai trabalhar, faz todo o serviço doméstico, almoça com o filho, dá banho nele, lê histórias. O pai super-herói, porém, um dia não sai mais para trabalhar e assume as tarefas domésticas. A mãe, agora trabalhando fora em tempo integral, finalmente aparece de capa e é reconhecida pelo filho como "super".

Uma possível interpretação do conto baseada em um imaginário sociodiscursivo - mostrado, sobretudo, pela figura do super-herói - toma como altamente admirável a pessoa que trabalha fora, além de pretender defender a igualdade de gêneros, visto que a mãe assume essa posição social louvável. No entanto, perpetua-se a visão de derrota atribuída àquele que assume o trabalho doméstico, com a representação de um pai barbado, desarrumado, destituído de sua heroicidade. São comportamentos e valores comunicados pela narrativa que, por um lado, pretendem-se progressistas (na alternância de papéis atribuídos, tradicionalmente, ao homem e à mulher), mas, por outro, revelam-se preconceituosos quanto à desvalorização do serviço doméstico. É, em alguma medida, uma forma de perpetuar a avaliação coletiva que se faz acerca da esfera pública e da esfera privada, ainda que seja valorizada a capacidade da mulher para o trabalho fora de casa.

Ainda acerca da "visão que trazemos do mundo", é pertinente enfatizar sua importância para a construção da identidade do sujeito - que, na abordagem da Psicologia Social (MOSCOVICI, 2015), é sempre um tanto individual, um tanto coletiva. Seguindo essa linha de pensamento, Charaudeau (2015) afirma que a consciência identitária depende da alteridade, da percepção da diferença e do estabelecimento de uma relação intersubjetiva. Tendo sido percebida a diferença, é desencadeado um duplo movimento, de atração e de rejeição em relação ao outro. Na atração, apreende-se o outro e estabelece-se uma partilha, dividindo-se com ele algo em comum. Já na rejeição, a diferença é vista como ameaça. Nesse caso, a percepção da diferença é acompanhada, geralmente, de um julgamento negativo, que pode se consolidar em um estereótipo, um clichê, um preconceito.

[...] ao julgar o outro negativamente, protegemos nossa identidade, mas também caricaturamos a do outro e, por conseguinte, a nossa própria, persuadindo-nos de que 
temos razão face ao outro. Nesse sentido, o julgamento estereotipado é como o fenômeno da refração/reflexão de um raio luminoso sobre uma superfície líquida: o julgamento que faço do outro diz algo sobre o outro, deformando-o (refração); reciprocamente, esse julgamento diz algo sobre mim mesmo (reflexão). (CHARAUDEAU, 2015, p. 19. Grifos do autor.)

Adichie, em uma conferência intitulada $O$ perigo de uma história única (2019), discorre sobre várias de suas experiências que corroboram a tendência ao estereótipo relativo àquele que se mostra diferente de nós. Nos relatos que faz, ressalta como, quando criança, em uma época em que tinha acesso exclusivamente a livros estrangeiros, ela reproduzia o que ouvia sua mãe contar. Embora nigeriana, em suas narrativas, as personagens eram brancas e de olhos azuis, brincavam na neve, comiam maçãs, falavam muito como era maravilhoso o sol ter aparecido e tomavam cerveja de gengibre. A falta de variedade quanto aos livros favoreceu a construção de uma história única, que não condizia com sua experiência de vida. Mais tarde, quando se mudou para os Estados Unidos, percebeu a estupefação de sua companheira de quarto ao saber que uma africana como ela ouvia Mariah Carey em vez de sons tribais. Ela também conta como um professor lhe disse que o romance que escrevera não era "autenticamente africano" porque as personagens conduziam carros, não estavam esfomeadas.

Assim Chimamanda explica como uma história única cria estereótipos, que não são exatamente mentiras, mas são incompletos e fazem com que uma história única se torne a única história. Ainda segundo a escritora, muitas vezes, as histórias únicas costumam ser usadas pelo "poder" - nkali: "ser maior que o outro" (ADICHIE, 2019, p. 13) - contando a história de outra pessoa como se fosse sua história definitiva. Acrescenta-se, então, que nisso se baseia o processo de opressão, que faz o outro acreditar só poder viver aquela história única, subalterna, inferior. A linha abissal que separa sociabilidades metropolitanas e coloniais, opressores e oprimidos, vale-se exatamente de histórias únicas magistralmente criadas e impostas. 


\section{Fazer saber, fazer sentir e fazer crer narrando}

Feliz com meu cabelo firme e forte,/com cachos que giram, e o fio feito mole se enrola, vira cambalhota! Menininha, você é uma gracinha!/ Nosso crespo é de rainha! (HOOKS, 2018, s/p.)

Com o intuito de desconstruir algumas "histórias únicas" contadas, sobretudo, para as meninas/mulheres - e mais nocivamente às negras -, foram selecionadas obras que têm em comum a proposta de refletir acerca do lugar e do papel da mulher nas sociedades que, como é possível perceber no Brasil, ainda se pautam em um pensamento "colonial". Buscase, aqui, partir de um tratamento afirmativo do feminino por meio da linguagem utilizada nos contos ilustrados em tela. Para isso, serão apresentados alguns pressupostos teóricos que sustentarão os aspectos analisados.

Segundo a Semiolinguística, todo ato de linguagem é orientado pelo entorno de uma interação social, ou seja, pela situação de comunicação. Define-se o "jogo de expectativas" da troca comunicativa a partir das finalidades possíveis impostas pela situação de comunicação. No caso do conto ilustrado para crianças, pode-se afirmar que escritor e ilustrador (além do designer e do editor) colocam-se no papel de contadores de histórias, que participam desse jogo de expectativas a fim de produzir, por meio dos arranjos textuais, efeitos no interlocutor - no caso, o leitor/mediador/criança. O leitor, à medida que adquire experiências de leitura, já espera dos autores que uma história seja contada, que o título indique o tema, ou o protagonista, ou algum elemento que o capte para a leitura.

Podemos destacar que os efeitos visados pelos autores dos contos (mas, claro, nem sempre efetivamente produzidos) são da ordem do fazer saber, do fazer sentir e do fazer crer (CHARAUDEAU, 2006). Quem conta uma história faz saber o que aconteceu por meio dos mecanismos da narração, isto é, pelos elementos narrativos (que, no caso do conto ilustrado, podem ser configurados pela palavra ou pela imagem, de forma direta ou indireta): personagens, ambiente, tempo, fatos em relação de causa e consequência. Para fazer sentir, os autores utilizam mecanismos de patemização (CHARAUDEAU, 2007), aqueles que programam uma reação emocional de acordo com o imaginário sociodiscursivo de partilha. E, para fazer 
crer, os contadores da história se valem da projeção persuasiva (CHARAUDEAU, 2004) própria das narrações, ao conseguir a adesão do leitor por meio de sua identificação com os fatos narrados, com as personagens, com o conflito ali apresentado. Ao se identificar com a história, o leitor a "vive" como participante da experiência (ainda que virtualmente), abrindose afetiva e cognitivamente e, assim, deixa-se convencer a respeito de um tema.

Salienta-se que o "jogo de expectativas" também está fortemente vinculado ao imaginário sociodiscursivo e depende, do lado do produtor do ato de linguagem, de sua habilidade de implicitar sentidos de acordo com aquilo que ele sabe que seu interlocutor será capaz de entender; já do lado do interpretador/leitor, depende da capacidade de inferir os sentidos implicitados, não só de acordo com elementos da organização textual, mas, sobretudo, de acordo com repertório de saberes que mantém em sua memória e que consegue vincular com a materialidade textual. O universo referencial de ambos - ou seu pluriverso, de acordo com Santos (2020) -, produtor e interpretador, precisa estar minimamente ajustado para que a troca se efetive com sucesso.

No que concerne ao leitor em fase inicial de desenvolvimento, é preciso considerar que sua percepção quanto à estrutura narrativa está sendo adquirida paulatinamente. "Pistas técnicas", como códigos intratextuais, alusões e restrições genéricas, permitem a criação de expectativas relacionadas, por exemplo, ao suspense, à coesão textual, à maior ou menor importância de eventos, à paródia, à ironia (HUNT, 2010, p. 194). Pode-se acrescentar, porém, que, muitas vezes, o jogo de expectativas é orientado pela mediação, pela oralização do texto, pelo tom de voz, pelos gestos e mesmo por explicações necessárias à aquisição dessa estrutura e ao acesso a um determinado repertório mnemônico.

Outro aspecto assaz relevante no que diz respeito à configuração dos contos ilustrados é que seu material significante permite a fusão entre o mimético e o diegético (NIKOLAJEVA; SCOTT, 2011). A parcela imagética oferece ao leitor a ambientação, a encenação dos atos, o aspecto das personagens e suas expressões corporais/fisionômicas, trabalhando o processo mimético em função do caráter motivado do signo imagético, de acordo com as semelhanças 
entre o que se vê e a realidade que se conhece - embora o signo imagético provoque, em sua configuração (traços, cores, recursos plásticos), um efeito de ficção facilmente apreendido. Os dados espaciais são quase todos referidos por meio da imagem, assim como a simulação dos fatos. Já os dados temporais e as ações em sequência próprios do processo diegético são prioritariamente referidos por meio da palavra.

O ponto de vista da narração também é mais fortemente marcado na expressão linguística e, quando se trata de um narrador-personagem, para identificá-lo na imagem, quase sempre será necessário considerar a disjunção entre o que se diz (em primeira pessoa) e o que se mostra (quase sempre "em terceira pessoa", por meio da imagem "externa" de alguém que o leitor precisa identificar como sendo o narrador-personagem). Assim, o modo enunciativo de organização do discurso de que fala Charaudeau (2008), que organiza a expressão em primeira pessoa (elocução), em segunda pessoa (alocução), ou em terceira pessoa (delocução), trabalha, nos contos ilustrados, em uma dualidade semiótica que precisa frequentemente se ajustar a favor da coesão e da coerência textual.

Em Uma princesa nada boba, de Luiz Antonio, com ilustrações de Biel Carpenter (2011), essa dualidade semiótica - mas convergente - é muito bem trabalhada. "Ouvimos" a voz da protagonista, uma menina que gostaria de ser princesa, ou de ser "igual a uma princesa", com "cachinhos dourados", "longos fios escorridos", "narizinho pontudo", que ostenta um nome de princesa: "Stephanie", "com P e H", como fazia questão de se apresentar. Ela se pergunta várias vezes: "Por que eu não podia ser igual a uma princesa?" E relata: "Minha mãe, a professora, tinha respostas para todos os seus alunos. Sempre respondia com a calma do mar sem ondas. Suas palavras gingavam, se esquivavam e escapavam. Minha filha, você é uma princesa" (ANTONIO, 2011, s/p).

Nesse trecho, que é parte da sequência narrativa introdutória, a narradora-personagem se coloca em seu "lugar de fala" e, ao mesmo tempo, interpela o leitor por meio da pergunta tão repetida: por que ela não poderia ser igual a uma princesa, ou mesmo uma princesa? Reconhecemos seu protagonismo e sua voz pela expressão em primeira pessoa, elocutiva, que prevalece ao longo da narrativa: "As aulas estavam acabando. Rezei. Quero voltar para a escola com cabelo 
de princesa, rosto de princesa, roupa de princesa" (ANTONIO, 2011, s/p.). Porém, a ilustração que acompanha essas frases apresenta delocutivamente a personagem, como alguém de quem se fala.

As páginas do livro são ocupadas pelas ilustrações e pela palavra na posição vertical, alongando para o alto a visão constante de uma menina que parece não querer se revelar, identificada pela silhueta, pela saia colorida, pelas meias listradas cobrindo as pernas inteiramente, pelo guarda-chuva que cobre a parte superior do tronco e a cabeça, sempre de lado ou de costas para o leitor. A contiguidade entre palavra (em primeira pessoa) e imagem (em "terceira pessoa", já que mostra uma pessoa disjungida daquela que fala), no mesmo espaço das páginas duplas, faz convergir as duas linguagens, dando a entender que se trata de uma mesma referência: a menina.

Esse dado pode parecer um tanto óbvio, porque o leitor experiente estabelece a relação entre palavras e imagem quase instantaneamente. Entretanto, é preciso observar que não se trata de um entendimento "natural"; a interpretação dessa convergência entre palavra e imagem se baseia em uma inferência relacionada à apreensão da superfície textual, que se organiza de determinada maneira de acordo com certo condicionamento imposto pela cultura, pelo imaginário sociodiscursivo. O objeto livro no qual o texto se apresenta é culturalmente identificado, assim como a maneira de lê-lo. Esse, em particular, subverte parcialmente o processo leitor, apresentando o texto verticalmente e, portanto, obrigando o leitor a uma linearidade diferente, não mais da esquerda para a direita e de cima para baixo, mas de cima para baixo e da esquerda para a direita, causando uma estranheza que se alia à outra estranheza que quer provocar quanto à temática trazida pela narrativa.

O foco narrativo inicial, marcado pela passagem do pretérito imperfeito para o perfeito, relata a mudança de ambiente e de ares vivida pela menina: "O colo de minha avó eram as minhas férias. Naquele janeiro, fui para o sítio. A minha casa tem guarita, portão eletrônico, cachorro. O sítio tem mato, rio, sapos." (ANTONIO, 2011, s/p). À pergunta repetida da neta, a avó responde com outra pergunta, que desconserta a menina, ao romper o limite do estereótipo, da "história única" acerca das princesas: "Minha neta, que tipo de princesa você 
quer ser?". A menina retruca: "Hã? Como assim 'que tipo de princesa'?" (ANTONIO, 2011, s/p.), mas fica sem resposta da avó, que a manda dormir.

Na sequência seguinte, a menina encontra, no rio onde fora despejar as flores que a avó usara em seu banho no dia anterior, uma moça muito bonita - na verdade, Oxum -, que repete a pergunta da avó e lhe mostra um abebé, um espelhinho, onde a menina vê inúmeras princesas, totalmente diferentes das que ela conhecia: inteligentes, nada bobas, como Oyá, princesa, guerreira, destemida, ou como Nzinga Mbandi, que lutou contra a invasão portuguesa na África. E então a menina se vê princesa. Na sequência final, quando volta para a escola após as férias, assume finalmente seu verdadeiro nome: Odara - nome de princesa nada, nada boba.

Parece ser possível mostrar, a partir dessa síntese da narrativa, como atua o modo descritivo de organização do discurso a favor das visadas para fazer saber, fazer sentir e fazer crer. Segundo Charaudeau, o descritivo é um procedimento discursivo que se combina com o narrativo ou com o argumentativo para "ver o mundo com um olhar parado", dando existência aos seres ao nomeá-los, localizá-los e atribuirlhes qualidades. Descrever significa "identificar os seres do mundo cuja existência se verifica por consenso (ou seja, de acordo com os códigos sociais)" (CHARAUDEAU, 2008, p. 111). É o principal recurso para fazer saber. Essa identificação, entretanto, pode ser restringida ou relativizada pela situação de comunicação na qual se inscreve.

Torna-se bastante relevante, portanto, salientar algumas formas da descrição no conto Uma princesa nada boba. A começar pelo nome da personagem, que faz questão de ser Stephanie e, depois da consciência de sua identidade, de ser Odara. Para além da referência a um ser, os nomes encontram-se situados discursivamente de acordo com o imaginário de partilha. Esses nomes estão marcados axiologicamente e sua origem "estrangeira" define seu valor em duas sociabilidades opostas: Stephanie, nome de origem europeia (como a princesa de Luxemburgo, ou a de Mônaco), reconhecidamente como característico de princesas brancas, louras, de olhos azuis; Odara, nome relacionado à umbanda e ao candomblé e, com isso, ao universo da cultura afrodescendente e, portanto, mais ajustado a uma princesa negra e à sua ancestralidade, 
à sua linhagem de princesas ligadas à resistência do povo escravizado na Bahia.

Nas cadeias referenciais do texto, também são encontrados outros nomes relacionados a essa mesma ancestralidade africana: sambas ("Mas era a mesma felicidade daqueles sambas bem antigos"), abebé ("No espelhinho? No abebé"), Oyá ("Oyá foi uma princesa das terras onde hoje é a Nigéria"), Nzinga Mbandi, Ndongo ("Nzima Bandi foi princesa e depois rainha do reino de Ndongo), Ketu ("E vi a avó da avó da minha avó. Princesa, vinda de Ketu.") (ANTONIO, 2011, $\mathrm{s} / \mathrm{p}$.). Descrever, nesse conto, permite fazer saber um universo relacionado à ancestralidade africana de Odara, mergulhado em uma aura de positividade, acrescentando e afirmando novas representações ao imaginário do leitor.

Em geral, os teóricos que investigam os contos ilustrados defendem que a imagem é mais propícia à descrição e a palavra, à narração. Descrever, entretanto, exige nomes, qualificações, localizações dadas pela palavra; a palavra faz o "retrato" do mundo. A imagem (material, aquela impressa na página do livro) é, na verdade, muito mais adequada para a mostração das qualidades; para registrar um repertório visual igualmente marcado pela cultura, pelo imaginário.

Nas ilustrações de Uma princesa nada boba, além dos tons de marrom atribuídos à pele das personagens, o preto, o branco, o vermelho, o amarelo e o cinza se alternam na composição das figuras, também, em certa medida, fazendo alusão às cores de uma cultura nascida na África e, por desdobramento, oferecendo um repertório visual relacionado a essas ideias.

A imagem da menina parece se aproximar de acordo com um close obtido pela passagem das páginas: inicialmente, mais distante do foco do leitor, depois, à medida que vai contando sua história, expressando sua subjetividade, fica cada vez mais próxima. A menina, inicialmente mostrada de lado e de costas, escondendo a pele e o rosto, aparece, ao final da narrativa, de frente, com olhar firme em direção ao leitor, bonita, já moça, com lábios vermelhos e flor no cabelo. Cada um desses elementos imagéticos conduz a interpretação para a valorização desse "tipo de princesa", enfim totalmente identificada com sua origem. 

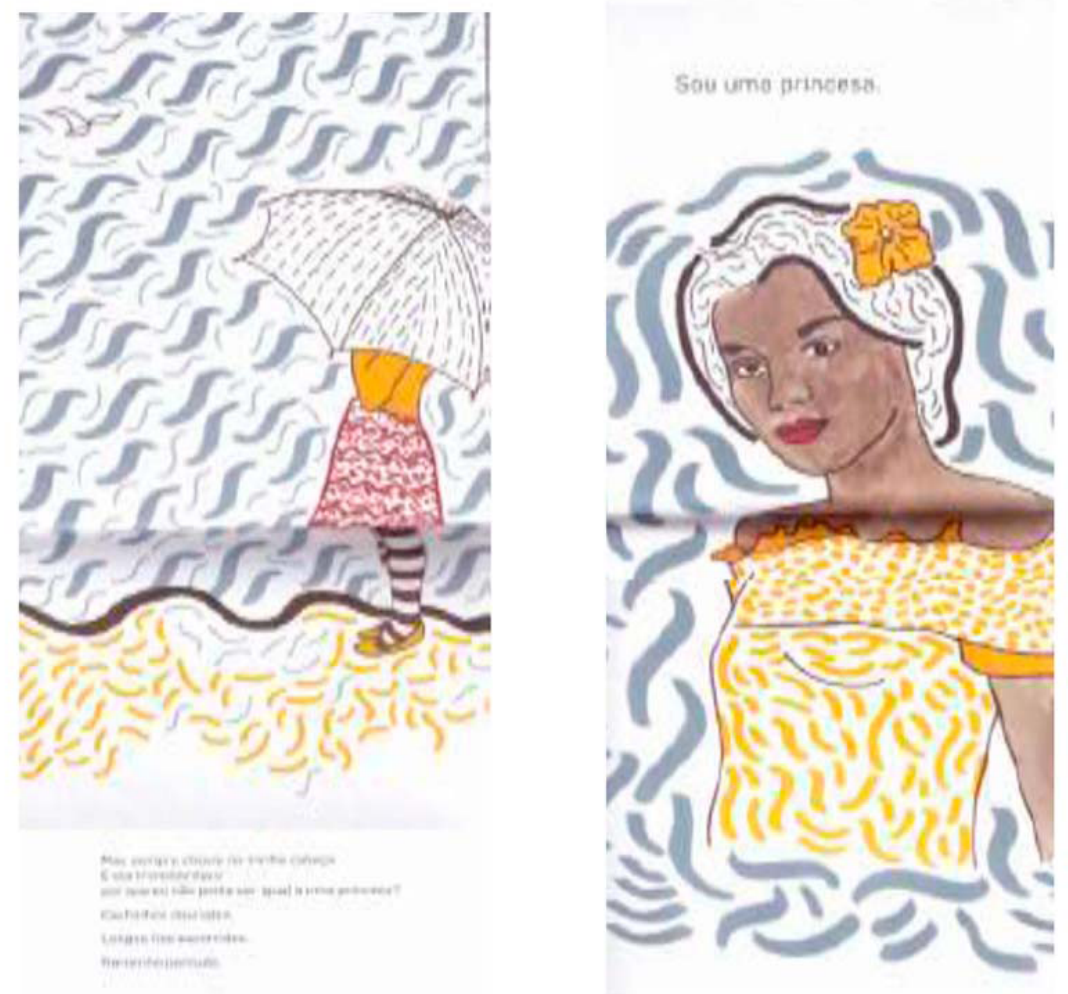

Figura 1 - Ilustrações de Biel Carpenter para Uma princesa nada boba. Fonte: ANTONIO (2011, s/p).

No processo da fazer saber pela descrição/mostração, uma parcela semiótica se ancora na outra, ora sendo a palavra a fixar o sentido da imagem, ora sendo a imagem a fixar o sentido da palavra. A referenciação verbo-visual pode não só ampliar o universo da significação em função dessa ancoragem, como também ajustar a leitura do "círculo hermenêutico" próprio na leitura de contos ilustrados:

A análise hermenêutica parte do todo, depois observa os detalhes, retorna ao todo com um entendimento melhor, e assim sucessivamente, em um círculo eterno conhecido como círculo hermenêutico. O processo de "ler" um livro ilustrado também pode ser representado por um círculo hermenêutico. Comecemos pelo signo verbal ou visual, um gera expectativas sobre o outro, o que, por sua vez, propicia novas experiências e novas expectativas. O leitor se volta do verbal para o visual e vice-versa, em uma concatenação sempre expansiva do entendimento. (NIKOLAJEVA; SCOTT, 2011, p. 14) 
A referenciação, seguindo os pressupostos da Linguística Textual (KOCH, 2005), é o processo de entrada de objetos de discurso no texto, a fim de indicar elementos no mundo e de promover a progressão das ideias de forma coesa, encadeada. O termo objetos de discurso salienta que palavras, expressões e, no caso desta proposta de análise, signos visuais são inseridos no texto não somente por seu significado prévio, recorrente na memória dos interagentes, mas principalmente pelo sentido que têm na trama textual, em função do contexto circunstancial e histórico no qual o texto se localiza. Dessa maneira, os objetos do discurso promovem uma referenciação circunstanciada, dependente da cadeia de signos disposta ao longo do texto e dos valores referendados socialmente com que se revestem.

No título, ocorre a primeira entrada de "uma princesa nada boba" na obra, criando uma expectativa para a leitura que ainda vai se iniciar. Como arquétipo (MIRA, 2017), "princesa" aciona o imaginário, resgatando valores como feminilidade, delicadeza, fragilidade, romantismo. Como objeto de discurso nesse texto, porém, "princesa", normalmente impregnada de uma axiologia ligada ao patriarcalismo que nutre a desvalorização da mulher - e que mais se refere às mulheres brancas -, é desconstruído pela qualificação "nada boba", que a diferencia do pressuposto de "subalternidade" relacionada ao feminino e perpetuada culturalmente, mas aqui julgada "boba".

A figura da princesa está [...] presente no nosso imaginário colectivo, envolvendo uma idealidade de prestígio social, uma concepção estética do corpo e de felicidade aliada ao discurso de amor romântico. Os significados que a cultura atribui a esta figura estão relacionados com a sua origem histórica que se mitificou na figura social ou imaginária [...]. (MIRA, 2017, p. 29)

Sendo um produto ideológico, consagrado com a posição de idealidade, a princesa acaba por ser uma figura mítica, na acepção barthesiana, descrevendo elementos da cultura que possuem um 'caráter imperativo, interpelatório' (Barthes, 1993:145). Transportando significados de uma cultura, o mito 'petrifica a intenção', transmitindo valores e ideologias dominantes e materializando discursos ideias, tendo um papel essencial na construção do imaginário colectivo e nos processos 
de identificação, transformando 'a realidade do mundo em imagem do mundo' (idem, 162).

Assim, é preciso ficar atento ao fato de o processo referencial estar mergulhado nas representações dos elementos referidos de acordo com o conhecimento partilhado entre autores e leitores - tanto para reproduzir um imaginário cristalizado, quanto para resistir a ele, propondo novas posturas, novos sentidos, novas interpretações.

Também nas inferências relacionadas às metáforas, o processo referencial é acionado. Por exemplo, ao longo da narrativa, Stephanie/Odara faz alusão ao fato de chover nela, primeiro, como expressão daquilo que a incomodava: "Mas sempre chovia na minha cabeça. E ela transbordava: por que eu não podia ser igual a uma princesa?" (ANTONIO, 2011, s/p.). Mais à frente, como expressão do começo de sua mudança interna, depois da ideia de haver variados "tipos de princesa" ter sido plantada pela avó: "Choveram pétalas amarelas no meu sonho" (ANTONIO, 2011, s/p). É uma chuva que cai na cabeça, insistindo em seu questionamento, ou, já em outro estado de alma, uma chuva de pétalas amarelas. São "chuvas" que expressam, nas qualidades que carregam e que podem ser "emprestadas" ao sentimento da personagem, em um primeiro momento, o incômodo do questionamento quanto à sua identidade, mas, depois, a leveza de uma resposta positiva em relação a essa identidade após ser valorizada.

Outras representações são trazidas à narrativa com o intuito de mobilizar conhecimentos e avaliações em nosso imaginário. As palavras da mãe em relação à pergunta da filha "gingavam, se esquivavam e escapavam", tais quais os movimentos da capoeira, adentrando o universo da cultura afrodescendente. Em "A minha casa tem guarita, portão eletrônico, cachorro. O sítio tem mato, rio, sapos" (ANTONIO, 2011, s/p.), o contraste dos espaços onde a personagem se localiza dado pela referenciação é igualmente o contraste das experiências que vive, não só por sua localização geográfica, mas por aquilo que os lugares representam para ela.

A casa, com elementos da urbanidade e da vida da classe média, marca, juntamente com a escola, o espaço em que sua inquietação nasce, no convívio com outras pessoas, provavelmente brancas e "aceitas" socialmente. O sítio, com elementos como mato, rio, sapos, é o espaço para descoberta 
de sua identidade, tão pregada a uma cultura que não separa o ser humano da natureza. Na ilustração, as princesas diferentes daquelas que ela conhecia, não só pelos cabelos, vestidos, castelos, mas por serem inteligentes e nada bobas, são figuradas como mulheres jovens, bonitas, altivas, adornadas com argolas e colares dourados; uma, com tiara estampada, outra, com uma coroa. Todos esses elementos incluem, na representação das mulheres, uma força feminina não dita, mas inferida por meio da imagem.

É possível perceber, nesses arranjos textuais, alguns recursos ligados à referenciação que, para além de fazer saber, têm o intuito de fazer sentir, em um processo denominado patemização (CHARAUDEAU, 2007). Como visada discursiva, a patemização tem o objetivo de programar, com o uso de representações sociais propícias a essa estratégia, o desencadeamento de emoções no momento da leitura. Não se trata apenas de utilizar palavras, gestos, imagens para indicar objetivamente uma emoção, dizendo "medo", "indignação", ou mostrando alguém com uma determinada expressão fisionômica relacionada à tristeza, por exemplo, mas de usar representações cujo "efeito colateral" seja uma emoção provavelmente despertada em qualquer membro de uma coletividade específica; elas guardam um "pressuposto afetivo". Por exemplo, há palavras como "carnaval", "feminicídio", "fascismo" e imagens como a de crianças brincando, ou a de um homem negro sendo morto por asfixia na entrada do supermercado que estão aptas, cada qual à sua maneira, a despertar emoções: alegria, horror, tristeza, revolta. Quando usadas em textos da mídia jornalística, por exemplo, podem estar ligadas à dramatização e à espetacularização dos fatos noticiados.

Na obra de Antonio (2011), emoções também são referidas por meio de metáforas linguísticas, como em "E meu pai trancava o rosto com os mais pesados cadeados. Com correntes grossas" (ANTONIO, 2011, s/p.) que provocam inferências afetivo-cognitivas. A reação emocional é programada, no sentido das visadas patêmicas, com trechos como o seguinte, que trazem ao leitor uma cena que evoca calma, tranquilidade: "Minha avó me deu um banho, cantando enquanto jogava água em mim" (ANTONIO, 2011, s/p). 
É igualmente possível obter uma reação emocional a partir de códigos inscritos na visualidade que compõe o texto: no início do texto, a sequência de oito páginas duplas mostra, a cada virada, quase a mesma imagem, mas sempre mais distante; primeiro, vê-se quase só o guarda-chuva aberto que cobre a menina; depois, além do guarda-chuva, parte inferior do corpo; depois, o corpo inteiro, cada vez menor, mais distante. A repetição de uma imagem, ainda que modificada em termos de distância em relação à visão do leitor, deve ser interpretada como passagem de tempo, e, no caso, como uma certa imobilidade, própria de quem está ensimesmada.

Ainda que não seja uma imagem impactante, é possível prever uma reação emocional a essa falta de movimento, de ação: a percepção da imobilidade pode incomodar, suscitando um sentimento, como compaixão, ou mesmo enfado. Ao final, a imagem que ocupa a página dupla, mostrando Odara de frente, altiva, contrasta com sua imagem inicial, servindo como evidência de sua transformação e, portanto, também pode sugerir uma emoção diversa, positiva, por parte do leitor, que, aderindo à narrativa, se regozija com a mudança interna vivida pela personagem e com a identidade assumida, agora visível.

Por fim, a visada para fazer crer incide sobre a projeção persuasiva que as narrativas engendram. Segundo Charaudeau (2004), há uma certa complementaridade entre a atitude impositiva característica da argumentação e a projetiva, própria da narração. A descrição das qualidades dos seres e de suas ações nas narrativas propõe uma trama de que o leitor/interlocutor pode fazer parte, identificando-se com as personagens e suas ações. No conto em questão, parte-se da premissa de que meninas negras também são princesas, para se chegar à conclusão de que a personagem - ou qualquer menina negra que se identifique com ela - também pode ser considerada uma princesa. Como argumento, é apresentado o protagonismo das princesas africanas, que Odara conhece no rio, olhando o abebé de Oxum, que são muito inteligentes, independentes e corajosas. Essas descrições são usadas como provas para que o interlocutor aceite a ideia de que meninas negras são também princesas e princesas ainda melhores do que as brancas, estas quase sempre frágeis e dependentes de um bom casamento, conforme o imaginário mais conservador estabelece. 
A resistência a um imaginário mais "conservador" é igualmente percebida em outra obra mais recente. O rapper Emicida (2018), bastante acostumado à resistência social em suas letras, lançou Amoras, com ilustrações de Aldo Fabrini. Em comum com Uma princesa nada boba, a trama se inicia com um questionamento que parte de uma menina: "Não há melhor palco para um pensamento que dança do que o lado de dentro da cabeça das crianças" (EMICIDA, 2018, p. 1). Ratificando a valorização da menina/mulher negra, nessa obra, também o encadeamento referencial presentifica um imaginário relacionado à ancestralidade africana: “[...] lá tudo é puro e profundo que nem Obatalá, o orixá que criou o mundo" (EMICIDA, 2018, p. 3).

A sequência narrativa principal é ambientada em um passeio pelo pomar, onde o narrador-personagem explica que "as pretinhas são o melhor que há" (EMICIDA, 2018, p.13); "Amoras penduradas a brilhar. Quanto mais escuras, mais doces" (EMICIDA, 2018, p. 17), em uma dupla referência às frutas e à menina, negra. A menina é descrita com qualidades de alguns dos nomes mais representativos da luta pela igualdade entre negros e brancos: "Forte como um lutador no ringue" - a ilustração ao lado da frase mostra Muhamed Ali - (EMICIDA, 2018, p. 21) "e gentil como Martin Luther King" - também representado imageticamente ao lado direito da página dupla (EMICIDA, 2018, p. 23); "Ao vê-la, Zumbi dos Palmares diria: - Nada foi em vão" - igualmente ilustrado ao lado da frase (EMICIDA, 2018, p. 25). E então a menina conclui: "Papai, que bom, porque eu sou pretinha também" (EMICIDA, 2018, p. 33).

Mais uma vez, para fazer saber, a narração do fato envolve a identificação e a qualificação das personagens pai e filha, mas sobressaem as semelhanças que a menina parece guardar de nomes emblemáticos, negros que são reconhecidos expoentes e que precisam ser sempre mais conhecidos, valorizados, espelhados e guardados na memória, tanto por seus nomes, quanto por suas imagens. Para fazer sentir, a parcela verbal apresenta delicadamente e com formas muito simples a identidade da menina a partir do duplo sentido dado às amoras e, metaforicamente, a ela. A força da descoberta de uma identidade tão bem valorizada é representada em páginas duplas, dita em letras grandes, com fundo colorido, fazendo 
reverberar no leitor a alegria do momento. Enfim, para fazer crer, a projeção persuasiva é obtida com a asserção de partida relacionada à tese de que as pretinhas são as melhores e com a de chegada, referente à menina, com a conclusão de que ela mesma é uma das melhores, por ser pretinha. Assumindo a função de asserções de passagens, as figuras negras emblemáticas com quem a menina é comparada reforçam a ideia defendida.

Pondé (2018), uma das pioneiras nos estudos sobre Literatura Infantil no Brasil, corrobora as ideias aqui apresentadas, afirmando, em $O$ renascimento de Vênus: a mulher na literatura infantil:

A leitura literária pôde surgir como uma contraideologia, no momento em que o capitalismo passou a assumir uma estrutura de dominação mais sutil, apropriando-se das consciências e dos corpos pela indústria cultural. Isso porque, através do plano simbólico da linguagem, pode provocar uma discussão dos papeis sociais, por intermédio da identificação (katarsis), na tentativa de despertar o indivíduo da alienação.

Nos tempos da economia globalizada, as fronteiras nacionais se diluem, um intenso intercâmbio planetário se realiza e grandes migrações vêm acirrar o problema das identidades. $\mathrm{O}$ processo de descolonização passou a rejeitar o eurocentrismo e valorizar o outro. Desconstruíram-se os paradigmas europeus, pois foi reconhecida a existência de pluralidades de destinos históricos e assim não há um único modelo que sirva para todos. (PONDÉ, 2018, p. 23)

Os contos Uma princesa nada boba (ANTONIO, 2011) e Amoras (EMICIDA, 2018) confirmam essa vocação para a contraideologia atribuída à Literatura, assim como colocam o foco das tramas na questão da identidade da menina/mulher negra, valorizando-a a despeito do padrão eurocêntrico tradicionalmente disseminado. E ainda reiteram a importância da representação coletiva: "Partilhar uma ideia, uma linguagem, é também confirmar uma ligação social e uma identidade" (PONDÉ, 2018, p. 65).

Pondé ainda explica que, ao comentarmos como um texto trabalha as representações, percebemos a intenção de reforço ou de contestação da ideologia dominante: "o lugar e a função que [os indivíduos] ocupam nas narrativas determinam os conteúdos representativos e sua organização" (PONDÉ, 
${ }^{1}$ Outros títulos poderiam ter sido citados aqui, entretanto, na limitação imposta pelo caráter deste texto, foram esses os selecionados por sua atualidade e sua exemplaridade em relação ao objetivo aqui proposto. Autores renomados como Ruth Rocha, Sylvia Orthoff, Ziraldo, Lygia Bojunga abriram espaço, desde a década de 1970, na Literatura brasileira, para a exploração de temas controversos em uma linguagem acessível às crianças, já com o intuito de promover a reflexão e a quebra de paradigmas.
2018, p. 65). E é isso que buscamos mostrar na breve análise dos contos aqui proposta: a centralidade da menina/mulher negra, "destituída" da marginalidade usual apregoada por uma cultura preconceituosa e discriminadora, agora valorizada adequadamente ${ }^{1}$.

\section{"Corazonar" com contos ilustrados}

Se contos ilustrados com destinação preferencial às crianças em fase inicial de socialização podem ser configurados a partir de sua literariedade para fazer saber, fazer crer e fazer sentir, acredita-se que sejam considerados um bem cultural forjado para o "corazonar" (SANTOS, 2020), para pensarmos com o coração, com o afeto, em nossa corporalidade. Na escola, onde esses contos costumam circular como material educativo que une ética e estética, exige-se do mediador de leitura um refinamento crítico tanto na seleção, quanto no trabalho com esse meio tão relevante de iniciação social da criança.

Apesar de sua suposta "lateralidade" como literatura, muitas vezes menosprezado em sua força comunicativa e artística como bem cultural e como gênero discursivo/literário, o conto ilustrado pode garantir recursos discursivos bastante profícuos para uma atitude de resistência ao pensamento hegemônico ocidentalocêntrico. Não que a Literatura direcionada para crianças precise exagerar em um possível caráter pragmático que se sobreponha ao literário, ao contrário: ainda mantendo a poeticidade em tramas às vezes singelas, outras vezes, consideradas "fraturantes" (RAMOS, 2011), difíceis para crianças, esse gênero pode propiciar, na urdidura feita com palavras e imagens, a exposição de temas sociais de urgente tratamento.

Atenta-se, porém, que a Literatura dita Infantil é "sem idade", pois alcança também as crianças, e, portanto, é igualmente de boa recepção do público não infantil - porque é Literatura, sem adjetivos (ANDRUETTO, 2012). Ainda que a leitura feita por um receptor experiente, cujo processo de socialização já esteja desenvolvido, possa imprimir sentidos diversos daqueles que um leitor iniciante consiga inferir, o sentido global do conto provavelmente será o mesmo. No caso dos livros que trabalham temas relacionados à resistência social, a diferença de leitura será a de uma socialização baseada 
em uma pedagogia libertadora, como quer Freire (2018): para os menos experientes, os contos mostrarão um modo de ver o mundo; para os mais experientes, um modo de revê-lo.

Alguns desses contos, como aqueles explorados, colocam a temática sobre a representação da mulher - e da mulher negra - em foco; em outros, a afirmação da negritude e da mulher negra se faz presente apenas indiretamente, por exemplo, em ilustrações que destacam personagens negros e elementos culturais relacionados à cultura afrodescendente, como na coleção escrita por Elisa Lucinda e ilustrada por Graça Lima (2010, 2011a e 2011b): em poemas tratando da poesia, "a menina transparente"; da alegria, "a dona da festa", e da liberdade, "a rainha das escolhas", as protagonistas figuradas são meninas negras; a ambientação e os outros personagens trazem muitos elementos da brasilidade e da negritude.

Já na coleção da Editora Mazza, adaptações de contos de fadas tradicionais trazem ao protagonismo crianças negras: em Cinderela e Chico Rei (AGOSTINHO; COELHO, 2015), ambientada em Vila Rica, o príncipe que oferece o baile é Chico Rei, um ex-escravizado que enriquecera. Em Chapeuzinho Vermelho e o boto-cor-de-rosa (AGOSTINHO; COELHO, 2020), a menina, negra, que morava às margens do Rio Negro, ganhara uma capa vermelha com capuz para se proteger da chuva que caía todos os dias.

Esses são exemplos de como a afirmação da menina/ mulher negra ganha, aos poucos, espaço no imaginário sociodiscursivo que, agora, é direcionado para a positividade de representações relacionadas a ela e, paralelamente, contra um sexismo sempre mais duro e opressor quando a mulher é negra. Segundo bel hooks (2019, p. 70), “[d]esafiar a opressão sexista é um passo crucial na luta pela dominação de todas as formas de opressão", por ser uma prática de dominação que a maior parte das pessoas vive, seja no papel de quem discrimina, seja no de quem é discriminado. Ainda segundo a autora, como os sistemas de opressão estão ligados uns aos outros, ao lutar contra um, esbarra-se na luta contra o outro; ao lutar contra o sexismo, é preciso lutar também contra a discriminação da mulher negra especificamente; lutar contra a discriminação da mulher negra é também lutar pela diminuição da desigualdade social. 
Bens culturais como contos ilustrados que valorizam a menina negra mostram uma sociabilidade decolonial, que luta contra uma discriminação imposta cognitiva e discursivamente por sociabilidades metropolitanas; contra o pensamento hegemônico que oprime para ter poder sobre os outros. Contos assim mostram, para ambos os lados da linha abissal que divide as sociabilidades e impõe um tratamento sub-humano ao oprimido, que há outra perspectiva, positiva, que revê a opressão pelo lado do oprimido, afirmando sua identidade e mostrando ao opressor outro modo de encarar aquele que é diferente, não menor.

Sabemos que há livros direcionados para crianças os quais pasteurizam as histórias, eliminando delas tudo que é visto como "impróprio para a idade" e para a reflexão, para o questionamento de valores ostentados por uma sociedade tão desigual - alguns dos quais referendados oficialmente pelas instituições do governo, outros, pelo imperialismo econômico colorido da Disney, por exemplo. Para os mediadores, atribui-se a tarefa de questionar, no momento da leitura, junto às crianças, exatamente esse tratamento pasteurizado, provocando o pensamento dos leitores em formação, sem eliminar as obras, mas mostrando o que se omite nelas - no mínimo. Toda criança precisa se sentir representada pelas personagens, pelas narrativas, pelo espaço ocupado nas histórias que são contadas - histórias que também são suas - ou deveriam ser.

Michèle Petit (2010) mostra resultados transformadores na partilha de leitura promovida em vários "espaços de crise", nos quais as pessoas são levadas a se identificar com narrativas para tratar de sua existência: "os livros lidos ajudam algumas vezes a manter a dor ou o medo à distância, transformar a agonia em ideia e a reencontrar a alegria" (PETIT, 2010, p.3334). Acrescenta-se, aqui, que a leitura mediada com a criança e a seleção crítica de livros são dois recursos poderosos de afirmação de valores silenciados e de discussão daquilo que parece natural, mas é construído discursiva e socialmente, e que causa, muitas vezes, um sofrimento injusto, como afirma Santos (2020).

Quando a mediação é realizada por um professor, o compromisso com o diálogo, com o questionamento e com a abertura para novas realidades pode - e deve - ser materializado nas leituras partilhadas com os estudantes, e 
não para eles, pela apresentação não só das pluralidades que constituem o mundo, como também de uma forma de tratá-las inclusivamente.

\begin{abstract}
A sala de aula, com todas as suas limitações, continua sendo um ambiente de possibilidades. Nesse campo de possibilidades temos a oportunidade de trabalhar pela liberdade, de exigir de nós e de nossos camaradas uma abertura da mente e do coração que nos permita encarar a realidade ao mesmo tempo em que, coletivamente, imaginamos esquemas para cruzar fronteiras, para transgredir. Isso é a educação como prática de liberdade. (HOOKS, 2020, p.273)
\end{abstract}

As diretrizes nacionais apregoam que "a escola, como espaço de aprendizagem e de democracia inclusiva, deve se fortalecer na prática coercitiva de não discriminação, não preconceito e respeito às diferenças e diversidades" (BRASIL, 2018, p.14). Apesar disso, sabe-se que a mediação crítica de leitura, sobretudo na escola, pode ser apenas um trabalho pontual de mudança no sistema de pensamento, de alcance aparentemente curto, mas sempre válido, porque profundo. No caso dos contos ilustrados em tela, esse trabalho está direcionado para uma sociologia das emergências daqueles que precisam ter sua identidade afirmada, positivada, garantida. A análise do processamento leitor que evidencia imaginários sociodiscursivos e os mecanismos de fazer saber, fazer sentir e fazer crer parece contribuir não só para a crítica dos contos ofertados para as crianças, mas, sobretudo, para uma mediação ciente de seu poder transformador.

\title{
REFERÊNCIAS
}

ADICHIE, Chimamanda Ngozi. O perigo de uma história única. São Paulo: Companhia das Letras, 2019.

AGOSTINHO, Cristina; COELHO, Ronaldo Simões (adaptação). Chapeuzinho Vermelho e o boto-cor-de-rosa. Ilustrações de Walter Lara. Belo Horizonte: Mazza Edições, 2020. 
AGOSTINHO, Cristina; COELHO, Ronaldo Simões (adaptação). Cinderela e Chico Rei. Ilustrações de Walter Lara. Belo Horizonte: Mazza Edições, 2015.

ALPHEN, Jean-Claude. Super. São Paulo: Pulo do Gato, 2017.

ANDRUETTO, María Teresa. Por uma literatura sem adjetivos. São Paulo: Pulo do Gato, 2012.

ANTONIO, Luiz. Uma princesa nada boba. Ilustrações de Biel Carpenter. São Paulo: Cosac Naify, 2011.

BARTHES, Roland. Fragmentos de um discurso amoroso. 7.ed. Rio de Janeiro: Francisco Alves, 1988.

BRASIL. Ministério da Educação. Base Nacional Comum Curricular. Brasília, 2018.

CHARAUDEAU, Patrick. Identidade linguística, identidade cultural. In: LARA, Graça Proença; LIMBERTI, Rita Pacheco. Discurso e (des)igualdade social. São Paulo: Contexto, 2015. p. 13-30

CHARAUDEAU, Patrick. Linguagem e discurso: modos de organização. São Paulo: Contexto, 2008.

CHARAUDEAU, Patrick. Discurso político. São Paulo: Contexto, 2006.

CHARAUDEAU, Patrick. A patemização na televisão como estratégia de autenticidade. In: MENDES Emília; MACHADO Ida Lucia (org.). As emoções no discurso. Vol. II. Campinas: Mercado Letras, 2010. p.23-56

CHARAUDEAU, Patrick. Pathos e discurso político. In: MACHADO, Ida Lúcia; MENEZES, William; MENDES, Emília (orgs.). As emoções no discurso. Vol. I. Rio de Janeiro: Lucerna, 2007. p. $240-251$

CHARAUDEAU, Patrick. A argumentação talvez não seja o que parece ser. In: GIERING, Maria Eduarda; TEIXEIRA, Marlene. Investigando a linguagem em uso: estudos de Linguística Aplicada. São Leopoldo: Editora da Universidade do Vale do Rio dos Sinos, 2004. p. 33-44 
COLOMER, Teresa. Introdução à literatura infantil e juvenil atual. São Paulo: Global, 2017.

EMICIDA. Amoras. Ilustrações de Aldo Fabrini. São Paulo: Companhia das Letrinhas, 2018.

ESTEVES, João Pissarra. Sociologia da comunicação. 2.ed. Lisboa: Fundação Calouste Gulbekian, 2016.

FREIRE, Paulo. Pedagogia do oprimido. 66.ed. Rio de Jsneiro/São Paulo: Paz e Terra, 2018.

HOOKS, bel. Teoria feminista. São Paulo: Perspectiva, 2019.

HOOKS, bel. Meu crespo é de rainha. Ilustração de Chris Raschka. Trad. Nina Rizzi. São Paulo: Boitatá, 2018.

HOOKS, bel. Ensinando a transgredir: a educação como prática da liberdade. 2.ed. São Paulo: Editora WMF Martins Fontes, 2017.

HUNT, Peter. Crítica, teoria e literatura infantil. São Paulo: Cosac Naify, 2010.

$\mathrm{KOCH}$, Ingedore. Referenciação e orientação argumentativa. In: $\mathrm{KOCH}$, Ingedore; MORATO, Edwiges Maria; BENTES, Anna Christina. Referenciação e discurso. São Paulo: Contexto, 2005. p. 33-52

LUCINDA, Elisa. A dona da festa. Ilustrações de Graça Lima. Rio de Janeiro: Galerinha Record, 2011a.

LUCINDA, Elisa. Lili, a rainha das escolhas. Ilustrações de Graça Lima. Rio de Janeiro: Galerinha Record, 2011b.

LUCINDA, Elisa. A menina transparente. Ilustrações de Graça Lima. Rio de Janeiro: Galerinha Record, 2010.

MIRA, Rita. O arquétipo da princesa na construção social da feminilidade. Lisboa, Edições Colibri, 2017.

MOSCOVICI, Serge. Representações Sociais: investigações em Psicologia Social. 11.ed. Petrópolis: Editora Vozes, 2015. 
NADAL, Beatriz Gomes. A escola como instituição: primeiras aproximações. In: Olhar de Professor, vol. 14, núm. 1, 2011, p. $139-150$

NIKOLAJEVA, Maria; SCOTT, Carole. Livro ilustrado: palavras e imagens. São Paulo: Cosac Naify, 2011.

PETIT, Michèle. A arte de ler ou como resistir à adversidade. 2.ed. São Paulo: Editora 34, 2010.

PONDÉ, Glória. O renascimento de vênus: a mulher na literatura infantil. São Paulo: Sesi-SP Editora, 2018.

RAMOS, Ana Margarida. A literatura para a infância em Portugal: últimas tendências. In: OLIVEIRA, Ieda de (org.). O que é qualidade em literatura infantil e juvenil: com a palavra o educador. São Paulo: DCL, 2011. p.201-218

SANTOS, Boaventura de Sousa. O fim do império cognitivo: a afirmação das epistemologias do Sul. Belo Horizonte: Autêntica, 2020.

ZIRALDO. Flicts. 30a. ed. São Paulo: Melhoramentos, 1999. 


\section{ABSTRACT}

\section{Analysys of loving discourse in illustrated tales: a contribution to the sociology of emergencies}

According to Boaventura de Sousa Santos (2020), the sociologies of absences and emergencies are at the heart of resistance against western-centered hegemonic thinking in order not only to identify the ways in which non-existance, radical invisibility and irrelevance of opressed social groups are produced, but also to value symbolically and politically the minority knowledge arising from struggle, experience, injust suffering, corporeality and from "corazonar", that is, from "hot" affective rationalization. This article is directed, in particular, to the sociologies of emergencies, with the intention of contributing to the instrumentalization of critical reading mediators, concerned with resistance to a prejudiced collective imaginary in relation to social minorities. Thus the purpose of this reflection is to problematize the illustrated tale - cultural asset aimed primarily at children in the early stage of socialization and, therefore, more susceptible to the inculcation of values analysing its singular verb-visual constitution in relation to the communication contract to which is linked in order to evaluate its potentiality as a resource for a liberating pedagogy. It is based on the assumption that the hybrid configuration of the illustraded tale allows a complex implication of senses and feelings that is quite conducive to the aesthetic treatment of themes related to sociability, without losing poeticiy, in a movement apparently in tune with the "coronazar" defended by the epistemologies of the South. For this, the analysis of the selected illustraded stories will be supported, primarily, by the Semiolinguistic Theory of Discourse Analysis, especially in what concerns the construction of sociodiscursive imaginary.

Keywords: Sociology of emergencies. "Corazonar". Semiolinguistics. Loving speech. Illustraded tales. 
Beatriz dos Santos Feres é mestre e doutora em Letras/Estudos da Linguagem pela UFF. É professora de Língua Portuguesa do Instituto de Letras da UFF, atuando na graduação, na Especialização e no Programa de Pós-Graduação em Estudos da Linguagem. É líder do Grupo de Pesquisa em Semiolinguística - Leitura, fruição e ensino e membro do Grupo de Trabalho em Linguística do Texto e Análise da Conversação da Anpoll. É autora de "Leitura, fruição e ensino com os meninos de Ziraldo" e organizadora, com Rosane Monnerat, de "Análises de um mundo significado: a visão semiolinguística do discurso", ambos da EdUFF, além de vários artigos e capítulos, incluindo " $\mathrm{Da}$ interpretação à compreensão de textos", no livro "Semiolinguística aplicada ao ensino", da Contexto. 